\title{
"Prevalence of role stressors and associated factors among health surveillance assistants in Malawi? A cross-sectional study"
}

Simon Ntopi ( $\sim$ sntopi892@gmail.com )

University of Malawi Kamuzu College of Nursing https://orcid.org/0000-0001-8889-6064

Ellen Chirwa

University of Malawi Kamuzu College of Nursing

Alfred Maluwa

"Malawi University of Science and Technology"

\section{Research article}

Keywords: health surveillance assistants, role ambiguity, role conflict, role overload, role stressors

Posted Date: February 19th, 2020

DOI: https://doi.org/10.21203/rs.2.23982/v1

License: () (i) This work is licensed under a Creative Commons Attribution 4.0 International License. Read Full License 


\section{Abstract}

Background: Health Surveillance Assistants (HSAs) are community-based health workers in Malawi, responsible for health services delivery at the community level. The prevalence of high role stressors among health surveillance assistants (HSAs) is a very important issue to strengthen the delivery of the essential health package at the community level; however, data on the prevalence of these role stressors to help understand more about the role stressors among HSAs is unavailable. This study aimed to investigate the prevalence of role stressors and its associated factors among HSAs.

Methods: A cross-sectional study design was used in this study to collect data from January 2017 to December 2017. Data were collected from 430 HSAs from the districts of Mangochi, Lilongwe and Mzimba using a self-administered structured questionnaire was hand delivered to a total of 455 HSAs (response rate of 94.5\%). Role ambiguity and role conflict was measured using a 13-item Rizzo et al. role conflict and ambiguity (RCA) scale; role overload was measured using a 9-item Reilly role overload scale and the job tasks for HSAs were measured using Burgal et al. modified version of the task inventory scale. Factors for role stressors were analyzed using the principal component analysis (PCA) and multiple linear regression model.

Results: Of the respondents $3 \%$ had high risk for RA, $51.20 \%$ RC and 49\% RO. Role stressors are prevalent among HSAs in Malawi. HSAs who were resident in rural areas, female, and performing additional clinical roles experienced significant levels of role stressors. Interestingly, no statistically significant associations were found between role stressors and the years at service post, age and the district of work.

Conclusion: This is the first study of occupational role stressors in Malawi. Role stressors are prevalent among HSAs. Interventions aimed at improving supervision, training and task regulation by an independent regulatory body may support to reduce role stressors among HSAs. Keywords : health surveillance assistants, role ambiguity, role conflict, role overload, role stressors

\section{Background}

In Malawi, there is a critical shortage of health workers where the doctor/patient ratio is very high. Additionally, there has been a growing demand for health care in Malawi especially with the advent of the HIV/AIDS pandemic [1]. To meet this high demand for health care, task shifting has been advocated where some of the roles of medical doctors have been delegated to junior cadres such as clinical officers and Health Surveillance Assistants (HSAs). Task shifting is the delegation of tasks to people who are in lower positions [2,3]. Its implementation is wholly supported by the WHO, which recommends each country introducing task shifting through $\mathrm{CHWs}$ should have a National Framework to guide the roles and training of $\mathrm{CHWs}[2,3]$.

The HSAs cadre has its routes from the Alma Ata declaration in Russia, in 1978 [4]. The meeting was a high-level global meeting organized by the World Health Organization (WHO) and United Nations Children's Fund (UNICEF) [5]. The meeting was attended by official government representatives from all over the world and UNICEF member countries. At the meeting, the role of the community health worker (CHW) was well defined [5]. Formerly, they were known as smallpox vaccinators or cholera assistants and were renamed HSAs immediately after the Alma Ata declaration [4]. HSAs are a group of one of the community-based health workers in Malawi. Historically, the role of the HSAs focused mainly on the delivery of preventive health services such as hygiene and sanitation promotion, immunization, and health education [6]. Since then, the HSAs' role has expanded to include clinical roles such as integrated community case management (iCCM) and HIV related work which all are delivered under the essential health package (EHP) programme [4,7].

With this expanded role, there is a general feeling among HSAs and other health workers that the HSAs are stressed [3]. Role stressors in the literature often times have referred to the terms such as role conflict, role ambiguity, and role overload [9]. Role conflict has been defined as conflicting situations that may arise at the workplace and may affect their compliance [10]. An example to this could be a conflicting situation that may arise between the HSAs and their supervisors or coworkers at the workplace. A very likely example to this is a situation where an HSA reports to two supervisors; one supervisor may need the HSA while the HSA is busy with the other supervisor. Situations like this are likely to cause role conflict at the workplace. Role ambiguity is defined as when employees lack some clarity on their roles [10]. A good example to this could be the introduction of a new role without proper orientation or guidelines for the workers [4,5].. Role overload is defined as when employees have too many roles or tasks to perform [10]. This is likely to happen when employees do not have adequate time for them to perform other roles such as those related to work or family because they have too many roles. All this has the likelihood to contribute towards role stress, lower work performance and lower job satisfaction [11].

Generally, information about role stressors among health workers in Malawi is scanty. Studies have been conducted elsewhere in the developed or developing countries in Asia ${ }^{[9-12]}$ on other professions such as nurses, accounting personnel and teachers. The studies conducted have shown role stress is an important area that needs to be prioritized because the continued presence of role stressors eventually affects the work performance and the job satisfaction of the employees $[10,13,14]$. We conducted this study to investigate more about the prevalence of the role stressors and its associated factors among HSAs in Malawi so that we can inform the policy makers about the problem.

\section{Methods}

\section{Study design}

A cross-sectional study design was used in this study. The cross-sectional study design was chosen based on the fact that it was appropriate for investigating the prevalence of the role stressors and its associated factors at a single given point in time [15]. 
The study was conducted in districts of Mangochi, Lilongwe and Mzimba South which represented the south, centre and northern regions of Malawi respectively. Specifically, the study was carried out in health facilities such as health centres and hospitals. Lilongwe district had both urban and rural representation and its inclusion was t for comparative purpose. The study period was from January 2017 to December 2017

\section{Participants}

The study participants were HSAs. Overall, the population of HSAs in the three districts was 1924.The sample size for the study was 385 HSAs and was calculated based on Lemeshow et al. ${ }^{16}$ sample size calculation formula for a cross-sectional study. Since studies to investigate role conflict, role ambiguity and role overload had not been conducted in Malawi, it was assumed that $50 \%$ of the HSAs were affected by the phenomenon. $20 \%$ was factored in considering the rate of the non-responses. This increased the sample size to 462 with a response rate of $93.5 \%$. Missing data was handled using pairwise deletion.

We conducted multistage sampling at several stages such as national and district levels to select districts and health facilities respectively to ensure the study results were generalizable. All the 29 districts were listed together with their HSAs population for PPS sampling. PPS sampling was chosen because it accorded an opportunity of selecting districts and health facilities with high numbers of HSAs. All HSAs working in the three selected districts under the government of Malawi payroll and working in either CHAM or Ministry of Health facilities and had work experience of two or more years were eligible to participate in the study.

\section{Data Collection}

A standardized face to face self-administered questionnaire having five sections was used to measure study variables. The first section collected sociodemographic data, while the subsequent sections collected data on HSAs task prioritization (as taken from the HSAs job description), role conflict and role ambiguity and role overload using adapted instruments. To adapt some items for the questionnaires, permission was sought from the American Psychological Association (APA), the University of Minnesota Vocational Psychology Research through the Rights Link of the Copyright Clearance Centre.

\section{Measurements}

Role conflict and ambiguity was assessed by a role conflict and ambiguity (RCA) scale developed by Rizzo et al. ${ }^{19}$ to measure role conflict and role ambiguity. The scale in total had 14 items, 6 items for role ambiguity and 8 items for role conflict. The scale was a 5-point Likert-type response format (from $1=$ 'strongly disagree' and $5=$ 'strongly agree'). The RCA scale was chosen because it has been widely used in literature and is the most dominant tool used in role conflict and role ambiguity studies $[17,18]$.

The Role Overload Scale (ROS) developed by Reilly ${ }^{23}$ was adapted and used to measure role overload. The ROS is a 13- item questionnaire ("there are too many demands on my time") with a 5-point Likert-type response format (from 1 = 'strongly disagree' and $5=$ 'strongly agree'). The tool had a Cronbach's alpha of 0.88 . Other researchers had found the Cronbach's alpha ranging from 0.89 to 0.94 [20-22].

The task inventory scale developed by Burgel et al(23) was adapted and used in this to collect information on HSAs job tasks. The instrument has been used in previous studies by Mbambo ${ }^{24}$ and $\mathrm{Uys}^{25}$ in studies related to job analysis of selected health workers in a district health system in KwaZulu-Natal for the South African PHC package of services. The instrument was modified and tasks not relevant to this study were removed and replaced with HSAs tasks contained in their job description to develop a final instrument. For each task, two options were required: to tick in the most appropriate box whether the task applied to the setting and the frequency the task was carried out (less than once per week, 1-5 times per week, 6-10 times per week and more than ten times per week). In addition, the questionnaire had a demographic section where all information pertaining to demographic variables were collected.

Sociodemographic variables collected during the survey included age, gender, marital status, location and education level and clinical performance. Age of the respondents was categorized into age groups as follows: $26-35,36-45,46-55$ and 56-60. Education was categorized according to certificates obtained at different education levels such as primary School Leaving Certificate (PSLCE), Junior Certificate of Education (JCE) and Malawi School Certificate of Education (MSCE). Age, education, gender, marital status and location were used in analysis.

The original items of the questionnaire were translated into Chichewa vernacular language using back translation by a group of HSAs lead by two professionals in the field of community health. The translated questionnaire was pilot tested with 36 HSAs at Nkhotakota District Hospital to evaluate the questionnaire wording and understanding of the questions. Some challenges with wording were found and corrected and this pilot sample findings were not included in the main study.

We used internal consistency to assess the reliability of the scales and subscales especially those for role stressors the RCA and the ROS. This was carried out to find out if there was consistency in the way the respondents responded to the items on the questionnaire. Cronbach's alpha (a) was used for this purpose. The RCA and the ROS had all a Cronbach's alpha $\geq .70$. Originally, the authors had high Cronbach's alpha ranging from .80 to .90 but this was deemed acceptable since the instruments were adapted and translated into the vernacular language (Chichewa) which is commonly spoken in most districts in Malawi. An alpha value of $\geq 0.70$ is desirable, although values that are slightly below 0.70 are usually considered acceptable [26].

\section{Search strategy}

The literature search was performed in HINARI, Google Scholar, and Google search engine and PubMed. The search terms included terms such as role stressors, role conflict, role overload, role ambiguity.

\section{Statistical Analysis}


The statistics used in the analysis included mean, chi-square and principal component analysis (PCA) and multiple linear regression. Since we did not have global questions for role stressors the mean was used in calculating the overall mean scores for role stressors. The chi-square was used to test relationships between variables. The PCA was used to identify factors for role stressors and multiple regression was used to estimate the predictor of HSAs role stressors and to control confounders.

\section{Results}

We analyzed 430 respondents, of which $50.2 \%$ were male. The majority of the respondents were within the age range of 36 to 45 years. The perception levels of role stressors were: role ambiguity $1.76 \mathrm{M}$ (95\% Cl: 1.69-1.83), role conflict $3.40 \mathrm{M}$ (95\% Cl: 3.32-3.49) and role overload 3.18 M (95\% Cl: 3.09-3.27) (Table 1).

Role ambiguity was significantly high in respondents with the following demographic characteristic: female respondents $14.25 M(95 \%$ l: $13.53-14.76, p=$ .020), JCE holders $14.38 \mathrm{M} \mathrm{(95 \%} \mathrm{Cl:} \mathrm{13.47-17.63,} p=.008)$, clinical roles $14.87 \mathrm{M}$ (95\% Cl:13.59-14.87) and HSAs resident in urban areas $14.14 \mathrm{M}(95 \% \mathrm{Cl}$. $13.53-14.76, p=.000)$. Role conflict was significantly slightly high in female HSAs $24.20 \mathrm{M}$ (95\% Cl: 23.40-25.00, p= .004), PSLCE 24.88 M(Cl: 20.60-29.15, p.001), clinical roles $23.87 \mathrm{M} \mathrm{(Cl:} \mathrm{23.23-24.51,} \mathrm{p}=.001)$, HSAs in urban areas $24.84 \mathrm{M} \mathrm{(95 \%} \mathrm{Cl:} \mathrm{23.48-26.20,} \mathrm{p}=.000)$ and years at service post $11-19$ years 24.42 M (95\% Cl: 23.54-25.41, p= .000). Role overload was significantly slightly high in Diploma holders $32.75 \mathrm{M}(95 \% \mathrm{Cl}$ : $29.22-36.28, \mathrm{p}=.000)$, clinical roles $28.76 \mathrm{M} \mathrm{(95 \%} \mathrm{Cl:} 27.87-29.66, \mathrm{p}=.000)$, HSAs in rural areas $28.77 \mathrm{M} \mathrm{(95 \%} \mathrm{Cl:} \mathrm{27.86-29.69,} \mathrm{p}=.000)$ and 11-19 years at service post M (95\% Cl: $27.49-29.89$ (Table 2). Table 3 shows HSAs tasks were significantly related to the role stressors. In terms of role ambiguity, it was only drug dispensing that was not related to role ambiguity. Role conflict was related to all the HSAs job tasks while role overload was related to all except water chlorination.

Table 4 shows a PCA analysis carried out aimed at identifying factors for the role stressors. Three factors contributing to role ambiguity were extracted. The first factor explained $45.26 \%$ of the total variance while all the three components explained $73.63 \%$ of the total variance (Table 4 ). The extraction was done with a loading factor value of 0.7 and all factors with an eigen value above 1.00 were eligible for selection. Component 1 loaded on three items which reflected on the 'Supervisor' with an eigenvalue of 3.62, Component 2 loaded on three items which reflected on 'role clarity' with an eigenvalue of 1.27 and Component 3 loaded on one item which reflected on 'work guidelines' with an eigenvalue of 1.00 (Table 4).

Two factors contributing to role conflict were extracted after conducting the PCA analysis. The first factor explained $33.19 \%$ of the total variance while all the two factors combined explained $54.64 \%$ of the total variance (Table 4 ). The extraction was carried out with a factor loading value of 0.7 and loaded three items on Component 1 with an eigenvalue of 2.32 which reflected on 'incompatibility' and two items on Component 2 with an eigenvalue of 1.50 which reflected on 'time \& person values' (Table 4).

Three factors contributing to role overload were extracted after conducting the PCA. The first factor explained $45.26 \%$ of the total variance while all the three factors when combined explained $63.04 \%$ of the total variance. In this analysis, Component 1 loaded 2 items, Component 2 loaded 2 items and Component 3 loaded 1 item. Component 1 items reflected on issues of 'time pressure' with an eigenvalue of 3.37 while, Component 2 reflected on the issue of 'task overload' with an eigenvalue of 1.20 and Component 3 reflected on issues of 'work prioritization' with an eigenvalue of 1.11 (Table 4).

Table 5 shows social demographic characteristics of the participants that were factors for role stressors after multiple linear regression. In terms of role ambiguity location, clinical work, antenatal care (ANC), growth monitoring (GM), HIV/AIDS and malaria rapid diagnostic testing (MRDT) were predictors for role ambiguity. The predictors for role conflict were location, gender, GM, MRDT, Village Health Committee (VHC) meetings, Family Planning and home-based care (HBC) while education level was the only predictor for role overload.

Table 1: Frequency of HSAs by degree of role stressor (low, moderate, and high) with $95 \% \mathrm{Cl}$ in each of the three role stressors

\begin{tabular}{|c|c|c|c|c|c|c|}
\hline & & $\begin{array}{l}\text { RA }(M=1.76, \text { Std. Dev=0.74, }(95 \% \\
\text { Cl:1.69-1.83) }\end{array}$ & & $\begin{array}{l}\mathrm{RC}(\mathrm{M}=3.40, \text { Std. Dev }=0.89,95 \% \mathrm{Cl} \text { : } \\
3.32-3.49)\end{array}$ & & $\begin{array}{l}\mathrm{RO}(\mathrm{M}=3.18, \text { Std. Dev }=0.94 \text {, } \\
95 \% \mathrm{Cl}: 3.09-3.27)\end{array}$ \\
\hline Variables & $\mathrm{N}$ & $\%$ & $\mathrm{~N}$ & $\%$ & $\mathrm{~N}$ & $\%$ \\
\hline Low & 356 & 82.80 & 53 & 12.30 & 105 & $24.40(22.44-26.36)$ \\
\hline Moderate & 61 & 14.20 & 156 & 36.50 & 114 & 26.50 \\
\hline High & 13 & 3.00 & 221 & 51.20 & 211 & 49.00 \\
\hline
\end{tabular}

Abbreviations: RA Role Ambiguity, RC Role Conflict, RO Role Overload

Table 2 Role stressor score according to socio-demographic characteristics with $95 \% \mathrm{Cl}$ in each dimension 
$95 \% \mathrm{Cl}$

$95 \% \mathrm{Cl}$

$95 \% \mathrm{Cl}$

\begin{tabular}{|c|c|c|c|c|c|c|c|c|c|c|c|c|c|c|c|c|c|}
\hline Variable & $\mathbf{N}$ & $\%$ & $M$ & SD & LB & UB & $\mathbf{p}$ & $M$ & SD & LB & UB & $\mathbf{p}$ & $M$ & SD & LB & UB & $\mathbf{p}$ \\
\hline Age & & & & & & & .235 & & & & & .301 & & & & & .308 \\
\hline $26-35$ & 154 & 35.8 & 13.86 & 5.51 & 12.98 & 14.74 & & 24.3 & 6.5 & 23.26 & 25.34 & & 28.56 & 8.31 & 27.24 & 29.89 & \\
\hline $36-45$ & 221 & 51.4 & 13.87 & 5.78 & 13.1 & 14.64 & & 23.83 & 6 & 23.03 & 24.63 & & 29 & 8.62 & 27.85 & 30.14 & \\
\hline $46-55$ & 52 & 12.1 & 15.52 & 7.57 & 13.41 & 17.63 & & 22.32 & 6.2 & 20.6 & 24.05 & & 26.4 & 8.32 & 24.09 & 28.72 & \\
\hline $56-60$ & 3 & 0.7 & 11.33 & 2.1 & 6.16 & 16.5 & & 22 & 2.65 & 15.43 & 28.57 & & 31 & 4 & 21.06 & 40.94 & \\
\hline Gender & & & & & & & .023 & & & & & .004 & & & & & .120 \\
\hline Male & 216 & 50.2 & 13.84 & 6.02 & 13.03 & 14.65 & & 23.41 & 6.46 & 22.54 & 24.28 & & 28.5 & 8.72 & 27.32 & 29.67 & \\
\hline Female & 214 & 49.8 & 14.25 & 5.84 & 13.46 & 15.04 & & 24.2 & 5.94 & 23.4 & 25 & & 28.59 & 8.24 & 27.47 & 29.7 & \\
\hline Education & & & & & & & .008 & & & & & .001 & & & & & .000 \\
\hline PSLCE & 8 & 1.9 & 14.25 & 7.1 & 8.35 & 20.17 & & 24.88 & 5.11 & 20.6 & 29.15 & & 29.75 & 11.54 & 20.11 & 39.39 & \\
\hline JCE & 193 & 44.9 & 14.38 & 6.39 & 13.47 & 15.28 & & 23.62 & 5.95 & 22.77 & 24.47 & & 27.4 & 8.72 & 26.15 & 28.64 & \\
\hline MSCE & 217 & 50.7 & 13.98 & 5.53 & 13.24 & 14.73 & & 23.99 & 6.54 & 23.11 & 24.87 & & 29.28 & 8.14 & 28.19 & 30.38 & \\
\hline Diploma & 12 & 2.8 & 9.83 & 1.99 & 8.57 & 11.1 & & 22.75 & 5.1 & 19.51 & 25.99 & & 32.75 & 5.56 & 29.22 & 36.28 & \\
\hline $\begin{array}{l}\text { Clinical } \\
\text { roles }\end{array}$ & & & & & & & .010 & & & & & .001 & & & & & .000 \\
\hline Yes & 350 & 81.6 & 14.23 & 6.11 & 13.59 & 14.87 & & 23.87 & 6.11 & 23.23 & 24.51 & & 28.76 & 8.51 & 27.87 & 29.66 & \\
\hline No & 79 & 18.4 & 13.23 & 4.98 & 12.11 & 14.35 & & 23.5 & 6.67 & 21.99 & 25 & & 27.54 & 8.29 & 25.67 & 29.41 & \\
\hline Location & & & & & & & .000 & & & & & .000 & & & & & .000 \\
\hline Rural & 330 & 76.7 & 14.14 & 5.73 & 13.53 & 14.76 & & 23.54 & 6.14 & 22.88 & 24.19 & & 28.77 & 8.6 & 27.86 & 29.69 & \\
\hline Urban & 100 & 23.3 & 13.67 & 6.67 & 12.25 & 15.09 & & 24.84 & 6.39 & 23.48 & 26.20 & & 27.63 & 7.92 & 25.94 & 29.32 & \\
\hline $\begin{array}{l}\text { District of } \\
\text { Work }\end{array}$ & & & & & & & .235 & & & & & .995 & & & & & .785 \\
\hline Mangochi & 95 & 22.1 & 14.74 & 6.37 & 13.44 & 16.03 & & 23.98 & 6.37 & 22.68 & 25.28 & & 28.28 & 8.72 & 26.51 & 30.06 & \\
\hline Lilongwe & 278 & 64.7 & 13.86 & 5.88 & 13.16 & 14.56 & & 23.69 & 6.16 & 22.96 & 24.41 & & 28.18 & 8.39 & 22.96 & 24.42 & \\
\hline Mzimba & 57 & 13.3 & 13.81 & 5.43 & 12.37 & 16.03 & & 24.07 & 6.25 & 22.41 & 25.73 & & 30.7 & 8.29 & 28.5 & 32.9 & \\
\hline $\begin{array}{l}\text { Yrs at } \\
\text { Serv. Post }\end{array}$ & & & & & & & .065 & & & & & .000 & & & & & .016 \\
\hline$<10$ years & 300 & 80.6 & 14.5 & 6.12 & 13.08 & 15.92 & & 23.18 & 6.53 & 21.66 & 24.69 & & 27.5 & 9.52 & 25.29 & 29.7 & \\
\hline $\begin{array}{l}11-19 \\
\text { years }\end{array}$ & 63 & 16.9 & 13.73 & 5.92 & 12.91 & 14.55 & & 24.42 & 6.38 & 23.54 & 25.31 & & 28.69 & 7.52 & 27.49 & 29.89 & \\
\hline $\begin{array}{l}\geq 20 \\
\text { years }\end{array}$ & 9 & 2.4 & 14.1 & 5.55 & 12.93 & 15.22 & & 22.75 & 5.31 & 21.66 & 23.85 & & 28.04 & 7.52 & 26.49 & 29.59 & \\
\hline
\end{tabular}

Abbreviations: PSLCE Primary School Leaving Certificate, JCE Junior Certificate of Education, MSCE Malawi School Certificate of Education

Table 3 Role stressor score according to job tasks with $95 \% \mathrm{Cl}$ in each dimension 
Role Conflict

\section{Cl: $95 \%$}

[2, p

Cl: $95 \%$

M L B

Task

Vaccination

IEC

Sanitation

Chlorination

ANC

Salt testing

GM

TB Work

HIV/AIDS

DD

iCCM

MRDT

VHC

VHC

Meetings

$\begin{array}{lllllll}\text { FP } & 283 & 91.5 & 14.34 & 13.61 & 15.06 & \begin{array}{l}46.18 \\ (.006)\end{array}\end{array}$

HBC

Nutrition 38

N \% M L

L B

23.9

$\begin{array}{lll}430 & 85.6 & 14\end{array}$

$\begin{array}{lll}13.39 & 14.62 & . \otimes \\ 13.39 & 14.62 & .8\end{array}$

\begin{tabular}{|llllll}
430 & 85.6 & 14 & 13.39 & 14.62 & .1 \\
430 & 85.6 & 14 & 13.39 & 14.62 & 15.8 \\
& & & & & $(1.06 .8$
\end{tabular}

23.9

$23.27 \quad 24.52$

15.81
$(1.00)$

51.86

(.401)

75.13
$(.012)$

24.52

$23.27 \quad 24.52 \quad$.

$\begin{array}{llll}23.9 & 23.27 & 24.52 & . \text {. } \\ 23.9 & 23.27 & 24.52 & 95.84 \\ & & & (.000)\end{array}$

\begin{abstract}
[2, p
\end{abstract}
Role Overload

Cl: $95 \%$

[2, p

M L B

$28.73 \quad 27.86 \quad 29.6 \quad$.

$\begin{array}{lllll}28.73 & 27.86 & 29.6 & .8\end{array}$

$28.73 \quad 27.86 \quad 29.6 \quad$.

$28.73 \quad 27.86 \quad 29.6 \quad 50.23$

$23.84 \quad 23.2 \quad 24.49 \quad 56.84$

(.001)

$\begin{array}{llll}24.03 & 23.43 & 24.72 & 49.34\end{array}$

$\begin{array}{llll}23.74 & 23.11 & 24.37 & 102.59\end{array}$

$\begin{array}{llll}23.74 & 23.11 \quad 24.37 \quad(.000)\end{array}$

$\begin{array}{llll}24.03 & 23.36 & 24.7 & 69.80\end{array}$

69.80
$(.000)$

$\begin{array}{llll}23.66 & 22.98 & 24.34 & 73.49\end{array}$

$\begin{array}{lll}23.64 & (.000)\end{array}$

$23.79 \quad 23.04 \quad 24.54 \quad 73.49$

(.000)

7.49
$(.000)$

$\begin{array}{llll}23.2 & 22.22 & 24.19 & 144.36\end{array}$

(.005)

$\begin{array}{llll}23.3 & 22.4 & 24.19 & 129.53\end{array}$

(.000)

$\begin{array}{llll}23.97 & 23.32 & 24.61 & 84.55\end{array}$

(.003)

$\begin{array}{llll}24.18 & 23.43 & 24.93 \quad 64.00\end{array}$

$\begin{array}{llll}23.78 & 23.11 & 24.38 & 63.55\end{array}$

$(.000)$

$\begin{array}{llll}23.82 & 23.17 & 24.48 & 111.19 \\ & & (.000)\end{array}$

Abbreviations: GM growth monitoring, VHC Village Health Committees, iCCM Intergrated community case management, MRDT malaria rapid diagnostic

testing, ANC antenatal care, DD Drug Dispensing, IEC Information Education and Communication

\title{
Table 4: Summarized results for Principal Component Analysis
}

Page 6/12 


\begin{tabular}{llll} 
Variable & EV & \% of Var & Cum. Tot. \\
\hline Role Ambiguity & & & \\
\hline Supervisor & 3.62 & 45.26 & 30.3 \\
\hline Role clarity & 1.27 & 15.84 & 60.05 \\
\hline Guidelines & 1 & 12.53 & 73.63 \\
\hline Role Conflict & & & \\
\hline Incompatibility & 2.32 & 33.19 & 32.78 \\
\hline Time \& personal values & 1.5 & 54.64 & 54.64 \\
\hline Role Overload & & & \\
\hline Time pressure & 3.37 & 45.26 & 26.03 \\
\hline Task overload & 1.2 & 21.36 & 47.39 \\
\hline Prioritization & 1.11 & 15.65 & 63.04
\end{tabular}

Key: EV= eigenvalue, \% of Var= Percentage of variance, Cum. Tot. = Cumulative total

Table 5 Multiple linear regression analysis for the association factors with the high level of role stress and their principal components among HSAs 430 


\begin{tabular}{|c|c|c|c|c|c|c|c|c|c|c|c|c|c|c|c|}
\hline & & RA & & Cl: $95^{\circ}$ & & & $\mathrm{RC}$ & & Cl: $95 \%$ & & & & RO & Cl: 95 & \\
\hline & $B$ & SE & $\begin{array}{l}P \\
\text { value }\end{array}$ & $\mathbf{L}$ & B & $B$ & SE & $\begin{array}{l}P \\
\text { value }\end{array}$ & $\mathrm{L}$ & B & $B$ & SE & $\begin{array}{l}p \\
\text { value }\end{array}$ & $\mathrm{L}$ & B \\
\hline (Constant) & 1.799 & .034 & .000 & 1.733 & 1.866 & 3.135 & .778 & .000 & 1.605 & 4.666 & 1.907 & .962 & .048 & .015 & 3.798 \\
\hline District & .001 & .002 & .582 & -.003 & .006 & -.054 & .052 & .294 & -.156 & .047 & -.057 & .064 & .373 & -.182 & .068 \\
\hline Location & .018 & .006 & .004 & .006 & .031 & .350 & .144 & .016 & .066 & .634 & -.011 & .179 & .950 & -.362 & .340 \\
\hline Age & .002 & .003 & .418 & -.003 & .008 & -.131 & .069 & .059 & -.266 & .005 & -.037 & .085 & .666 & -.204 & .131 \\
\hline Gender & .005 & .004 & .203 & -.003 & .012 & .197 & .083 & .018 & .034 & .361 & .153 & .103 & .137 & -.049 & .355 \\
\hline Education Level & -.002 & .003 & .463 & -.009 & .004 & -.064 & .077 & .411 & -.216 & .088 & .201 & .095 & .036 & .013 & .389 \\
\hline $\begin{array}{l}\text { Experience at } \\
\text { work }\end{array}$ & .002 & .003 & .469 & -.004 & .008 & -.016 & .071 & .816 & -.155 & .122 & .006 & .087 & .942 & -.165 & .178 \\
\hline Clinical work & .013 & .005 & .014 & .003 & .024 & .023 & .122 & .848 & -.217 & .264 & -.210 & .151 & .166 & -.507 & .088 \\
\hline Chlorination & -.003 & .023 & .906 & -.048 & .043 & -.260 & .529 & .624 & -1.301 & .781 & .464 & .654 & .479 & -.823 & 1.750 \\
\hline ANC & -.033 & .008 & .000 & -.048 & -.018 & -.338 & .177 & .057 & -.687 & .011 & .410 & .219 & .062 & -.021 & .841 \\
\hline Salt testing & -.001 & .010 & .899 & -.020 & .017 & -.277 & .217 & .203 & -.705 & .150 & -.274 & .269 & .308 & -.803 & .254 \\
\hline GMP & -.051 & .017 & .003 & -.084 & -.017 & 1.432 & .392 & .000 & .661 & 2.203 & .246 & .485 & .612 & -.707 & 1.199 \\
\hline TB work & .005 & .006 & .439 & -.008 & .018 & -.029 & .148 & .844 & -.319 & .261 & .082 & .182 & .655 & -.277 & .440 \\
\hline HIV/AIDS & .011 & .005 & .039 & .001 & .021 & .000 & .121 & .999 & -.238 & .239 & -.056 & .150 & .707 & -.351 & .239 \\
\hline Drug Dispensing & -.006 & .004 & .148 & -.015 & .002 & .077 & .098 & .431 & -.115 & .269 & -.021 & .121 & .862 & -.258 & .216 \\
\hline ICCM & -.005 & .003 & .052 & -.010 & .000 & .019 & .059 & .754 & -.098 & .135 & .059 & .073 & .425 & -.086 & .203 \\
\hline MRDT & .019 & .004 & .000 & .012 & .027 & .182 & .083 & .030 & .018 & .346 & -.012 & .103 & .906 & -.215 & .191 \\
\hline $\begin{array}{l}\text { Sputum } \\
\text { collection }\end{array}$ & -.006 & .004 & .171 & -.014 & .003 & -.043 & .099 & .665 & -.238 & .152 & .067 & .123 & .586 & -.174 & .308 \\
\hline VHC meetings & .005 & .009 & .609 & -.013 & .022 & -.822 & .205 & .000 & -1.224 & -.419 & .277 & .253 & .273 & -.220 & .775 \\
\hline Family Planning & -.004 & .004 & .396 & -.012 & .005 & -.422 & .099 & .000 & -.617 & -.227 & -.168 & .123 & .171 & -.409 & .073 \\
\hline $\mathrm{HBC}$ & -.021 & .011 & .052 & -.042 & .000 & .798 & .245 & .001 & .316 & 1.280 & -.244 & .303 & .422 & -.840 & .352 \\
\hline Nutrition & .002 & .007 & .742 & -.012 & .016 & -.112 & .161 & .489 & -.429 & .206 & .104 & .199 & .603 & -.288 & .496 \\
\hline
\end{tabular}

Abbreviations: RA Role Ambiguity, RC Role Conflict, RO Role Overload, GM growth monitoring, VHC Village Health Committees, iCCM intergrated community case management, MRDT malaria rapid diagnostic testing, ANC antenatal care

\section{Discussion}

This is the first study to explore the prevalence of role stressors and related factors among HSAs in Malawi. We found $3 \%$ of HSAs had high scoring level of RA, with $51.20 \%$ scoring high for RC and $49 \%$ scoring high for RO. Working in rural area, performing clinical roles and carrying out tasks such as ANC, GM, HIV/AIDS and MRDT were factors for RA. Additionally, the supervisor, role clarity and work guidelines were identified as factors for RA. Work in an urban area, gender, GM, VHC meetings, family planning and home-based care were factors for RC. Additionally, inter-personal conflict and inter-role conflict were factors identified as predictors for RC. Education level along with time pressure, task overload and work prioritization were identified as factors for RO.

\section{Comparison with other studies conducted}

Compared to studies conducted in other countries, our study showed lower mean role ambiguity score and moderate mean role conflict and role overload scores. HSAs in the literature are generally regarded to have a high risk for role stress. Specifically, in this study HSAs were found with high role ambiguity (3\%), role conflict $51.20 \%$ and role overload $49 \%$ a situation which is likely to contribute to high role stress levels if role stress mitigation measures are not put in place. Our study is in agreement to the findings that sociodemographic characteristics (age, gender, education level, years at service post, location and performance of clinical roles) are contributory to role stress among employees. Thus, address of role stress among Malawian HSAs is still a very big challenge for the policy makers and researchers.

In line with studies conducted in Malawi, our findings showed the HSAs supervision is a challenge and was associated with a significantly higher risk of role ambiguity. HSAs are supervised by Assistant Environmental Health Officers (AEHOs) and their supervision is considered to be inadequate and unsupportive $[27,28]$. Evidence from the literature suggests supervision should be done regularly and that the supervisors should be experts in the field who should be able to provide new knowledge and actively engage the supervisees during supervision [29] which is not the case with the AEHOs. The AEHOs are considered as the 
principal supervisors for the HSAs and are supported by Senior HSAs (SHSAs), clinical officers and community nurses. In light of the expansion of the HSAs role, there is need for some adjustments regarding their scope of practice such as reducing the catchment population, training and providing stronger supportive supervision in order to prevent the role stressors [30]. Supervision really needs to be given a priority as the country has a critical shortage of clinicians and nurses to provide the requisite supervision. Some of the barriers that have been reported as barriers for effective supervision of $\mathrm{CHWs}$ include travel expenses and logistics for face to face interaction meetings with the $\mathrm{CHWs}$, lack of appropriate supervisory tools, inadequate understanding of $\mathrm{CHW}$ roles, and the poor general perception managers have towards CHWs supervision, lack of supervisory training and resources to provide a conducive climate for $\mathrm{CHWs}$ and their oversight due to some existing bureaucracies [31]. With the addition of clinical roles to their existing roles there is need for consistent and effective supervision of the HSAs. Poor supervision of workers has the potential to affect the job satisfaction and performance of employees [8]. Therefore, establishing an improved supervisory system for HSAs is an urgent need in order to control role stressors and increase their job satisfaction and work performance.

We observed in this study, location, working in an urban area and gender (female) had high risk for role conflict. Other literature evidences had similar and contrasting findings about our finding. For example, Cervoni et al. ${ }^{32}$ found no significant associations based on location (urban, suburban and rural settings) while Kok et al. ${ }^{28}$ found significant findings. Similarly, other literature evidence had mixed findings about gender, others have been in support of our finding while others have found male employees perceived a higher degree of role conflict. Evidence form the literature suggests female employees were more likely to experience role conflict due to the multiple roles they perform such as meeting both family and work obligations [33]. Additionally, in this study, we observed incompatibility as the most important predictor for role conflict. With the addition of new roles, the number of supervisors has also increased to accommodate their new clinical roles. Under such circumstances, role conflict is likely to occur based on the theory of the principle of unity of command which states that when an employee is being supervised by two or more superiors role conflict is likely to occur as an employee is meant to be responsible to one superior $[34,35]$. Therefore, it is necessary for the government to provide the necessary leadership for this to be done. If not properly handled, may lead to poor work performance and workers dissatisfaction [36].

We observed that HSAs location of work had an effect to high risk of role ambiguity among HSAs in rural areas. This finding is in agreement with Kok et al. ${ }^{28}$ who suggested that HSAs in rural areas are more disadvantaged than their colleagues in urban areas in terms of resource availability, reporting and supervision frequency. In such a situation, supervision can be a challenge as supervisors face difficulties to reach them either by road or phone due to poor network coverage and road infrastructure. Therefore, it is important for the policy makers to put this into consideration to ensure there is improved communication between the HSAs deployed in rural areas and their district offices. Additionally, we observed education level had an effect on high role overload especially among HSAs with a Diploma certificate.

We observed in this study that HSAs performing clinical roles were prone to higher risk of role overload. This finding is in agreement to Davis et al. ${ }^{37}$ who found $\mathrm{CHWs}$ working under pressure to provide services related to their new roles which has created high workload $[8,12,27,28,38]$. Additionally, time pressure was found as the most important predictor for role overload among HSAs and this has forced some HSAs to abandon their old existing roles [1,6] and only prioritize tasks perceived important $[1,12,37]$. However, considering the significant health gains the Ministry of Health in Malawi has made in achieving 4 out of 8 millennium development goals (MDGs) of which three are health related: reducing child mortality, combating HIV and AIDS, malaria and other diseases [39], this task shifting is not only necessary but relevant for the Malawi Ministry of Health as much of this achievement is attributed to HSAs work at the community level. Weighing at these achievements, their positive health outcomes and the growing demands for health care in Malawi due to the advent of HIV/AIDS and the prevalence of high maternal and child mortality, it is important to continue with the task shifting but with some regulation. It would be important if the Ministry of Health considered the use of independent bodies in monitoring HSAs task regulation.

\section{Limitations}

This study has some limitations. This study being a cross-sectional study and its results cannot institute cause and effect associations. Secondly, the selfreported questionnaire used in this study could have affected the study results. Thirdly, in Malawi there are other community-based health workers such as Enrolled Community Health Nurse Technicians and Assistant Environmental Health Officers were not included in the study. Fourthly, HSAs working in private institutions were not included in this study. Fifthly the issue of confounders such as age, gender and education status of the respondents have not been addressed in this study as they might have an effect on the relationships and contribute towards biasness of the results. Therefore, further prospective studies are required.

\section{Conclusion}

Considering that some HSAs tasks are correlated to role stressors, it is important that their address should be given a priority. If mitigation measures are not initiated, the role stressors would very likely contribute to low performance at work and lower job satisfaction among HSAs. Additionally stress conditions such as depression, dissatisfaction, anxiety and tension would arise [40]. Therefore, there is an urgent need by the authorities and partners to join hands to address these role stressors for the HSAs to continue enjoying high job satisfaction and good performance at work. This study, therefore, would like to recommend that Government should introduce measures that would control role ambiguity, role conflict and role overload levels in HSAs. This study, therefore, proposes to Government to introduce an independent regulatory body that would regulate HSAs tasks in Malawi. Additionally, supervision of HSAs should be intensified to overcome the role stressors. Since the HSAs role is broader than the roles of other health cadres it would be imperative to adopt an integrated approach towards the supervision of HSAs. This study, therefore, would like to propose interprofessional supervision (IPS) as an approach for the effective supervision of the HSAs in order to enhance HSAs supervision in Malawi. IPS involves supervision by supervisors from different professional disciplines [41]. This would help to address the challenges faced in the supervision of the HSAs, as their role is more interprofessional requiring supervisors from different 
health professional backgrounds. We propose this to start right at college by letting students from different professional background working and learning together in a class to ensure effective teams for supervision are formed for greater performance and improved health outcomes.

\section{Abbreviations}

DHOs: District Health Officer; HSAs: Health Surveillance Assistants; RCA: Role Conflict and Ambiguity; ROS: Role Overload Scale; RC=: Role Conflict; RA: Role Ambiguity; RO: Role Overload; CHW: Community Health Worker.

\section{Declarations}

\section{Acknowledgement:}

We thank all the health surveillance assistants who participated in this research.

Author Contributions: Study design: SN, EC, AM; Data collection and analysis: SN; SN, EC and AM critically reviewed the manuscript for content. All authors have read and approved the manuscript.

\section{Funding:}

This research received no specific grant from any funding agency in the public, commercial or not-for-profit sectors.

\section{Availability of data and materials:}

Data may be made available by contacting the corresponding author.

\section{Ethics approval and consent to participate:}

This study was approved by the College of Medicine Research Ethics Committee (COMREC). Informed consent was obtained from all the participants.

\section{Consent for publication:}

Not applicable

\section{Competing interests:}

The authors declare that they do not have competing interests.

\section{Authors' Details:}

1University of Malawi, Kamuzu College of Nursing, P/Bag 1, Lilongwe. 2University of Malawi, Kamuzu College of Nursing, P/Bag 1, Blantyre. 3Malawi University of Science and Technology, P.O. Box 5196, Limbe, Malawi

\section{References}

1. Hermann K, Van Damme W, Pariyo GW, Schouten E, Assefa Y, Cirera A, et al. Community health workers for ART in sub-Saharan Africa: learning from experience-capitalizing on new opportunities. Hum Resour Health. 2009;7(1):31.

2. Lehmann U, Sanders D. Community health workers: what do we know about them. State Evid Programme Act Costs Impact Health Outcomes Using Community Health Work Geneva World Health Organ. 2007;1-42.

3. WHO. Country health profile Malawi. Wolrd Health Organization, Geneva; 2013.

4. Malawi MoH. The health surveillance assistants, origins and current status. Ministry of Health; 2012.

5. Perry HB, Zulliger R, Rogers MM. Community health workers in low-, middle-, and high-income countries: an overview of their history, recent evolution, and current effectiveness. Annu Rev Public Health. 2014;35:399-421.

6. Smith S, Deveridge A, Berman J, Negin J, Mwambene N, Chingaipe E, et al. Task-shifting and prioritization: a situational analysis examining the role and experiences of community health workers in Malawi. Hum Resour Health [Internet]. 2014 May 2 [cited 2019 Oct 7];12(1):24. Available from: https://doi.org/10.1186/1478-4491-12-24

7. Malawi MoH. Guidelines for the Management of Task Shifting to Health Surveillance Assistants in Malawi. Ministry of Health; 2014.

8. Kadzandira JM, Chilowa W. The role of health surveillance assistants (HSAs) in the delivery of health services and immunisation in Malawi [Internet]. University of Malawi, Centre for Social Research; 2001. Available from: https://www.unicef.org/evaldatabase/index_14066.html

9. Trayambak S, Kumar P, Jha A. A conceptual study on role stressors, their impact and strategies to manage role stressors. IOSR J Bus Manag. 2012;4(1):44-8.

10. Kahn RL, Wolfe DM, Quinn RP, Snoek JD, Rosenthal RA. Organizational stress: Studies in role conflict and ambiguity. 1964; Available from: https://www.psc.isr.umich.edu/dis/infoserv/isrpub/pdf/Conflictandambiguity_2214_.PDF 
11. O’Brien MJ, Squires AP, Bixby RA, Larson SC. Role development of community health workers: an examination of selection and training processes in the intervention literature. Am J Prev Med. 2009;37(6):S262-9.

12. Smith S, Deveridge A, Berman J, Negin J, Mwambene N, Chingaipe E, et al. Task-shifting and prioritization: a situational analysis examining the role and experiences of community health workers in Malawi. Hum Resour Health. 2014;12(1):24.

13. Fakhry SF, El Hassan NAA. Causes and types of conflict and resolution strategies among nursing students: A comparative study between two cultures. $J$ Am Sci. 2011;7(4):808-15.

14. Rizzo JR, House RJ, Lirtzman SI. Role conflict and ambiguity in complex organizations. Adm Sci Q. 1970;150-63.

15. Polit DF, Beck CT. Nursing research: Generating and assessing evidence for nursing practice. 9th Edition. Philadelphia: Wolters Kluwer/Lippincott Williams \& Wilkins; 2014

16. Lemeshow S, Hosmer D, Klar J, Lwanga S. Adequacy of sample size in health studies. Baffins Lane, Chichester West Sussex P019 1 UD, England: John Wiley \& Sons Ltd; 1990

17. Khan A, Yusoff RBM, Khan MM, Yasir M, Khan F. Psychometric analysis of role conflict and ambiguity scales in academia. Int Educ Stud. $2014 ; 7(8): 104$.

18. Palomino MN, Frezatti F. Role conflict, role ambiguity and job satisfaction: Perceptions of the Brazilian controllers. Rev Adm. 2016;51(2):165-81.

19. Reilly MD. Working wives and convenience consumption. J Consum Res. 1982;8(4):407-18.

20. Pearson QM. Role overload, job satisfaction, leisure satisfaction, and psychological health among employed women. J Couns Dev JCD. $2008 ; 86(1): 57$.

21. Bellizzi JA, Hite RE. Convenience consumption and role overload convenience. J Acad Mark Sci. 1986;14(4):1-9.

22. Crouter AC, Bumpus MF, Head MR, McHale SM. Implications of overwork and overload for the quality of men's family relationships. J Marriage Fam. 2001;63(2):404-16.

23. Burgel BJ, Wallace EM, Kemerer SD, Garbin M. Certified occupational health nursing: Job analysis in the United States. AAOHN J [Internet]. 1997;45(11):581-91. Available from: https://doi.org/10.1177/216507999704501101

24. Mbambo S. A job analysis of selected health workers in a district health system in KwaZulu Natal-Part two: Job analysis of nurses in primary health care settings. Curationis. 2003;26(3):42-52.

25. Uys L. A job analysis of selected health workers in a district health system in KwaZulu Natal-Part one: Job analysis of nurses in hospital settings. Curationis. 2003;26(3):32-41.

26. Adams KA, Lawrence EK. Research methods, statistics, and applications. 2nd ed. Thousand Oaks, California: Sage Publications; 2018.

27. Martiniuk A, Smith S, Deveridge A, Berman J, Negin J, Mwambene N, et al. Getting Treatment and Care to the Last Mile: Analyzing the Health Surveillance Assistant Cadre in Malawi. vol. Discussion paper 10. Waterloo (Canada): Africa Initiative-Centre for International Governance Innovation; 2014.

28. Kok MC, Namakhoma I, Nyirenda L, Chikaphupha K, Broerse JE, Dieleman M, et al. Health surveillance assistants as intermediates between the community and health sector in Malawi: exploring how relationships influence performance. BMC Health Serv Res. 2016;16(1):164.

29. Hill Z, Dumbaugh M, Benton L, Källander K, Strachan D, ten Asbroek A, et al. Supervising community health workers in low-income countries-a review of impact and implementation issues. Glob Health Action. 2014;7(1):24085.

30. Jaskiewicz W, Tulenko K. Increasing community health worker productivity and effectiveness: a review of the influence of the work environment. Hum Resour Health. 2012;10(1):38.

31. Henry JV, Winters N, Lakati A, Oliver M, Geniets A, Mbae SM, et al. Enhancing the supervision of community health workers with WhatsApp mobile messaging: qualitative findings from 2 low-resource settings in Kenya. Glob Health Sci Pract. 2016;4(2):311-325.

32. Cervoni A, DeLucia-Waack J. Role Conflict and Ambiguity as Predictors of Job Satisfaction in High School Counselors. J Sch Couns [Internet]. 2011;9(1):n1. Available from: http://jsc.montana.edu/articles/v9n1.pdf

33. Al-Kahtani NS, Allam Z. A Holistic Approach to Determine the Relationship of Sociobiographical Variables with Role Ambiguity and Role Conflict. Int Bus Manag [Internet]. 2016 [cited 2017 Oct 15];10(15):2795-801. Available from: http://docsdrive.com/pdfs/medwelljournals/ibm/2016/2795-2801.pdf

34. Conley S, Woosley SA. Teacher role stress, higher order needs and work outcomes. J Educ Adm. 2000;38(2):179-201.

35. Flores HR. Middle Management Strategic Roles: Strategic Role Conflict and its Antecedents. 2016;

36. Ebbers JJ, Wijnberg NM. Betwixt and between: Role conflict, role ambiguity and role definition in project-based dual-leadership structures. Hum Relat. 2017;0018726717692852.

37. Olaniran A, Madaj B, Bar-Zev S, van den Broek N. The roles of community health workers who provide maternal and newborn health services: case studies from Africa and Asia. BMJ Glob Health. 2019;4(4):e001388.

38. Kalaya MJ. The effect of job incentives on the job satisfaction of Health Surveillance Assistants in Nsanje district, Malawi. 2014.

39. Office MNS. Malawi: MDG Endline Survey, 2014: Key Findings. National Statistical Office; 2014.

40. Duxbury L, Higgins C, Lyons S. The Etiology and Reduction of Role Overload in Canada's Health Care Sector. 2017.

41. Howard FM, Beddoe L, Mowjood A. Interprofessional supervision in social work and psychology in Aotearoa New Zealand. Aotearoa N Z Soc Work [Internet]. 2013;25(4):25. Available from: https://anzasw.nz/wp-content/uploads/Social-Work-Review-Volume-25-Number-4-Articles-Howard-BeddoeMowjood.pdf 


\section{Supplementary Files}

This is a list of supplementary files associated with this preprint. Click to download.

- STROBEchecklistcrosssectionalbmc.docx 